This item was submitted to Loughborough's Research Repository by the author.

Items in Figshare are protected by copyright, with all rights reserved, unless otherwise indicated.

\title{
The effects of high-intensity intermittent exercise compared with continuous exercise on voluntary water ingestion
}

\section{PLEASE CITE THE PUBLISHED VERSION}

http://journals.humankinetics.com/ijsnem-back-issues/ijsnem-volume-23-issue-5-october/the-effects-of-highintensity-intermittent-exercise-compared-with-continuous-exercise-on-voluntary-water-ingestion

\section{PUBLISHER}

(c) Human Kinetics Publishing as accepted for publication

\section{VERSION}

AM (Accepted Manuscript)

\section{PUBLISHER STATEMENT}

This work is made available according to the conditions of the Creative Commons Attribution-NonCommercialNoDerivatives 4.0 International (CC BY-NC-ND 4.0) licence. Full details of this licence are available at: https://creativecommons.org/licenses/by-nc-nd/4.0/

\section{LICENCE}

CC BY-NC-ND 4.0

\section{REPOSITORY RECORD}

Mears, Stephen A., and Susan M. Shirreffs. 2019. "The Effects of High-intensity Intermittent Exercise Compared with Continuous Exercise on Voluntary Water Ingestion". figshare.

https://hdl.handle.net/2134/20401. 
1 The effects of high intensity intermittent exercise compared to continuous exercise on 2 voluntary water ingestion

3

4 Stephen A Mears, Susan M Shirreffs

5 School of Sport, Exercise and Health Sciences, Loughborough University, Loughborough, 6 LE11 3TU, UK

7

8 Corresponding Author:

9 Stephen A Mears

10 School of Sport, Exercise and Health Sciences, Loughborough University, Loughborough, 11 LE11 3TU, UK

12 Telephone: 01509226352

13 Fax: 01509226301

14 Email: S.A.Mears@lboro.ac.uk

15

16 Running head: High intensity exercise and voluntary water intake 17 
18 Abstract

19 Water intake occurs following a period of high intensity intermittent exercise (HIIE) due to 20 sensations of thirst yet this does not always appear to be caused by body water losses. Thus, 21 the aim was to assess voluntary water intake following HIIE. Ten healthy males $(22 \pm 2 y$, $2275.6 \pm 6.9 \mathrm{~kg}, \dot{\mathrm{VO}}$ 2peak $57.3 \pm 11.4 \mathrm{ml}_{\mathrm{kg}} \mathrm{kg}^{-1} \cdot \mathrm{min}^{-1}$ ) (mean $\left.\pm \mathrm{SD}\right)$ completed two trials (7-14d apart). 23 Subjects sat for 30min then completed an exercise period involving $2 \mathrm{~min}$ of rest followed by $241 \mathrm{~min}$ at $100 \% \dot{\mathrm{V} O}{ }_{2 \text { peak }}$ repeated for $60 \mathrm{~min}$ (HIIE) or $60 \mathrm{~min}$ continuously at $33 \% \dot{\mathrm{VO}}_{2 \text { peak }}$ (LO). 25 Subjects then sat for 60min and were allowed ad libitum water intake. Body mass was 26 measured at start and end of trials. Serum osmolality, blood lactate and sodium 27 concentrations, sensations of thirst and mouth dryness were measured at baseline, postexercise and after 5, 15, 30 and 60min of recovery. Vasopressin concentration was measured at baseline, post-exercise, 5 and 30min. Body mass loss over the whole trial was similar 30 (HIIE: $0.77 \pm 0.50$; LO: $0.85 \pm 0.55 \%)(p=0.124)$. Sweat lost during exercise $(0.78 \pm 0.22 \mathrm{v}$ $310.66 \pm 0.26 \mathrm{l})$ and voluntary water intake during recovery $(0.416 \pm 0.299$ v $0.294 \pm 0.295 \mathrm{l})$

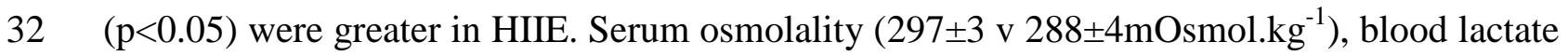
$33\left(8.5 \pm 2.7 \mathrm{v} 0.7 \pm 0.4 \mathrm{mmol}^{-1} \mathrm{l}^{-1}\right)$, serum sodium (146 $\left.\pm 1 \mathrm{v} 143 \pm 1 \mathrm{mmol}^{-1} \mathrm{l}^{-1}\right)$ and vasopressin $34\left(9.91 \pm 3.36\right.$ v 4.43 $\left.\pm 0.86 \mathrm{pg} . \mathrm{ml}^{-1}\right)$ concentrations were higher after HIIE $(\mathrm{p}<0.05)$ and thirst 35 $(84 \pm 7$ v 60 \pm 21$)$ and mouth dryness ( $87 \pm 7$ v 64 \pm 23$)$ also tended to be higher $(\mathrm{p}=0.060)$. Greater voluntary water intake after HIIE was mainly caused by increased sweat loss and the consequences of increased serum osmolality mainly resulting from higher blood lactate concentrations. 
Introduction

An increase in serum osmolality causing an increased release of vasopressin has been proposed as one of the mechanisms resulting in the sensation of thirst and water replacement (Stricker \& Verbalis 1988). Following the onset of exercise, loss of water from the vascular space results in a rise in serum osmolality (Convertino, Keil, Bernauer, \& Greenleaf, 1981). During and following continuous exercise, the resultant effect of increased osmolality and vasopressin release on voluntary water intake has been extensively studied (Cheuvront \& Haymes 2001; Dugas, Oosthuizen, Tucker, \& Noakes, 2009; Wong, Williams, Simpson, \& Ogaki, 1998), yet the effect on water intake following a bout of high intensity intermittent exercise (HIIE) is less well known. During and following HIIE, there is an increase in blood lactate concentration, which has been linked to the prevention of serum sodium uptake from the vascular space to the intracellular space, resulting in an increased serum osmolality (Nose et al., 1991). Nose et al. (1991) explored the link between exercise intensity, plasma lactate and plasma sodium concentrations. As submaximal exercise intensity increased, a significant rise in plasma sodium concentrations was observed which correlated strongly with changes in plasma lactate concentrations.

Bouts of high intensity exercise have also been shown to result in an increase in vasopressin release (Hew-Butler, Noakes, Soldin, \& Verbalis, 2008). For example, Hew-Butler et al. (2008) found that on completion of a maximal oxygen uptake test, vasopressin concentrations were significantly elevated compared to a submaximal bout of continuous exercise. However, subsequent water intake was not assessed so the affect of increased vasopressin release on sensations of thirst and voluntary water intake could not be established.

Following a period of high intensity exercise there is a shift in water from the vascular to the interstitial and intracellular spaces (Convertino et al., 1981; Nose et al., 1991; Sjøgaard, Adams, \& Saltin, 1985). The movement of hypotonic water out of the vascular space will contribute to the rise in plasma osmolality. Sjøgaard et al. (1985) analysed extra- and intracellular muscle water shifts following one-legged dynamic knee-extensions in six males. They attributed the movement of water to the interstitial space due to an increase in blood pressure and to an increase in perfused capillaries, whilst an osmotic gradient caused by an increase in lactate concentration was believed to cause water to move into the intracellular space. 
79 Despite the known effect of HIIE on the rise in serum osmolality and an increase in vasopressin release the effect on subsequent voluntary water intake is unknown. A rise in osmolality above the vasopressin release threshold of approximately $285 \mathrm{mOsmol} . \mathrm{kg}^{-1}$ (Thompson, Bland, Burd, \& Baylis, 1986) will lead to maximal anti-diuresis, resulting in an osmotically driven thirst signal, thus facilitating water intake. Following a bout of HIIE, increased serum osmolality above values experienced following continuous exercise of matched work, may result in a greater osmotic signal, ultimately leading to increased water intake. Excessive water intake may result in weight gain, which for weight bearing sports such as running may impair performance. In addition water intake may lead to increased urine output, which along with increased inconvenience may result in increased water losses

89 (Wong et al., 1998).

91 Depending on the duration of the HIIE, sweat losses may not be large enough to result in sensations of thirst (Wolf, 1950) or result in a level of dehydration that will impair performance (Sawka et al., 2007). Sensations of thirst have been shown to increase and result in voluntary water intake when body mass losses, reach and increase beyond approximately $0.8 \%$ (Wolf, 1950), whilst body mass losses of less than $2 \%$ can be tolerated without decrement in exercise performance (Sawka at al., 2007). However, despite this, water intake will usually occur after HIIE and suggests a mechanism independent of water losses is acting to increase sensations of thirst and subsequent voluntary water intake (Nose et al., 1991). As increased blood lactate concentration has been shown to affect serum sodium concentration and therefore serum osmolality (Nose et al., 1991), the question arises as to the influence of increased blood lactate concentrations on sensations of thirst and subsequent voluntary water intake.

103

104 It was hypothesised that the increase in lactate concentration, resulting from the high intensity 105 intermittent exercise, would increase serum sodium concentration and thus, serum osmolality, 106 in turn causing increased sensations of thirst and subsequent voluntary water intake and also 107 increased vasopressin release. 
Methods

110

111 Subjects

112 Ten healthy male subjects (age $22 \pm 2$ years, mass $75.6 \pm 6.9 \mathrm{~kg}$, height $1.78 \pm 0.08 \mathrm{~m}, \dot{\mathrm{V}}$

$113 \mathrm{O}_{\text {2peak }} 57.3 \pm 11.4 \mathrm{ml} \cdot \mathrm{kg}^{-1} \cdot \mathrm{min}^{-1}$ ) (mean $\pm \mathrm{SD}$ ) were recruited to take part in two trials,

114 undertaken in a counter-balanced order. All subjects had the experimental protocol explained

115 to them verbally and in writing. Subjects provided written informed consent and the

116 experiment was approved by the Loughborough University Ethical Advisory Committee.

118 Experimental protocol

119 Subjects were asked to visit the laboratory on four separate occasions for a $\dot{\mathrm{V}} \mathrm{O}_{2 \text { peak }}$ test, a

120 familiarisation trial and two experimental trials; high intensity intermittent (HIIE) and

121 continuous (LO) exercise. During the first visit $\dot{\mathrm{VO}}_{2 \text { peak }}$ was measured using a discontinuous

122 incremental test to volitional fatigue on an electrically braked cycle ergometer (Lode Corival;

123 Lode BV, Groningen, Netherlands). During the final minute of each four minute incremental

124 stage, expired gas was collected in Douglas bags and analysed for oxygen and carbon dioxide

125 concentration (Servomex 1400 Oxygen and Carbon Dioxide Gas Analyser; Servomex,

126 Crowborough, UK). Gas volumes and temperature were measured using a Harvard dry gas

127 meter (Harvard Apparatus Ltd., Edenbridge, UK) and thermometer (Edale Digital

128 Thermometer D515: Edale instruments Ltd., Cambridge, UK) and corrected to STPD

129 (standard temperature and pressure, dry). Subjects visited the lab a further three times for the

130 familiarisation trial and two experimental trials. The familiarisation trial was identical to the

131 HIIE trial. Prior to each experimental trial subjects were asked to consume $500 \mathrm{ml}$ of water

132 two hours before arrival at the laboratory to ensure they were in a euhydrated state and to

133 arrive after an overnight fast. In the 24 hours prior to the first experimental trial, subjects

134 were asked to record their dietary intake (food and drink consumed, amount and method of

135 preparation) and refrain from strenuous physical activity and consumption of alcohol. They

136 were then asked to repeat this before each subsequent trial.

138 The experimental trials were separated by a period of 7-14 days and began in the morning at the same time for each subject. Experimental trials were identical apart from the exercise

140 performed. A schematic outline of the experimental trial is presented in Figure 1. 
141 Experimental trial order was decided by incomplete Latin square design and subjects did not know which trial they were participating in when arriving at the laboratory for the first trial.

144 In each trial, on arrival, subjects voided and the whole urine volume was measured and a $5 \mathrm{ml}$ sample retained for later analysis and had nude body mass measured. Subjects were asked to insert a rectal thermistor $10 \mathrm{~cm}$ past the anal sphincter. Skin thermistors were attached at the chest, tricep, thigh and calf and a heart rate monitor was positioned (Polar Vantage; Kempele, Finland). Core $\left(T_{c}\right)$ and skin temperature $\left(T_{\text {sk }}\right)$ were measured continuously throughout the trials and a minute average was taken every 10 min (BIOPAC MP100 System; BIOPAC, Santa Barbara, CA, USA). Mean weighted skin temperature was calculated using the formula outlined by Ramanathan (1964). Subjects sat for $30 \mathrm{~min}$ to account for postural alterations in blood volume at $19.7 \pm 1.1^{\circ} \mathrm{C}$ and $30.7 \pm 10.5 \%$ relative humidity $(\mathrm{RH})$. Baseline heart rate values every $10 \mathrm{~min}$ were recorded and a $100 \mathrm{~mm}$ visual analogue subjective feelings questionnaire comprising of thirst and dry mouth scales was administered at the completion of the $30 \mathrm{~min}$ seated rest $(0 \mathrm{~mm}=$ not all thirsty/mouth not at all dry, 100 $\mathrm{mm}=$ very thirsty/mouth very dry). During the rest period a 21g cannula (Surflo, Terumo, Leuven, Belgium) was inserted into a superficial vein on the forearm to allow venous blood sampling. The line was flushed with 2-3 ml of heparinised saline. A baseline (B) blood sample $(7.5 \mathrm{ml})$ was collected at the end of the rest period. Subjects then cycled for a period of $60 \mathrm{~min}$ in $24.9 \pm 0.7^{\circ} \mathrm{C}$ and $51.1 \pm 2.1 \% \mathrm{RH}$. In the HIIE trial, they rested for $2 \mathrm{~min}$ and then performed 1 minute of cycling at a power output attempted to equal the maximum power achieved when recording $\dot{\mathrm{VO}}_{2 \text { peak }}(305 \pm 55 \mathrm{~W}$ ), however exact total work performed during the HIIE trial was not measured. This was repeated 20 times during the 60 minute period. In the LO trial, subjects cycled continuously at 33\% of their peak power output for $60 \mathrm{~min}(102 \pm 18 \mathrm{~W})$. Every $10 \mathrm{~min}$ in the LO trial, heart rate was recorded and subjects were asked to provide a rating of their perceived exertion (RPE) and thermal sensation. In the HIIE trial, this was performed at the end of a HIIE bout closest to the completion of a 10 min period. Immediately following completion of exercise (post-exercise, PE), a blood sample $(7.5 \mathrm{ml})$ was collected and thirst and dry mouth subjective feelings questionnaires were completed. Subjects were then seated for $60 \mathrm{~min}$ in $21.2 \pm 1.8^{\circ} \mathrm{C}$ and $29.5 \pm 10.3 \% \mathrm{RH}$ with tap water $\left(11 \pm 3^{\circ} \mathrm{C}\right)$ intake measured during each 30 minute period. The amount of water consumed was measured but the subject was not made aware of the volume or that the 
174 informed at the commencement of the recovery period that they could drink as they wanted

175

176

177

178

179

180

181

182

183

184

185

186

187

188

189

190

191

192

193

194

195

196

197

198

199

200

201

202

203

204

205

206

207 and that the bottle would be refilled if necessary. Heart rate and thermal sensation were measured every $10 \mathrm{~min}$. At 5, 15, 30 and $60 \mathrm{~min}$ a blood sample (7.5 ml) was collected and thirst and dry mouth subjective feelings questionnaires were completed. Subjects voided, the volume was measured and a $5 \mathrm{ml}$ sample was retained for later analysis and they then had nude body mass measured. After completion of the body mass measurement, subjects were allowed to leave the laboratory. Ambient temperature and relative humidity was measured at 10 minute intervals (RH85 Digital Thermo-Hygrometer; Omega, Manchester, UK).

\section{Sample analysis}

For each $7.5 \mathrm{ml}$ venous blood sample, $1.0 \mathrm{ml}$ was aliquoted and mixed with anticoagulant $\left(\mathrm{K}^{+}\right.$ EDTA; $1.5 \mathrm{mg} \cdot \mathrm{ml}^{-1}$ ) for analysis of haemoglobin concentration, haematocrit and glucose concentration. A further $5.0 \mathrm{ml}$ was aliquoted and mixed with anticoagulant ( $\mathrm{K}^{+}$EDTA; 1.5 $\mathrm{mg} \cdot \mathrm{ml}^{-1}$ ) and from this, plasma was separated and frozen at $-80^{\circ} \mathrm{C}$ for later analysis of hormone concentration. The remaining blood $(\sim 2.0 \mathrm{ml})$ was allowed to clot and was centrifuged at $3000 \mathrm{rpm}$ for $15 \mathrm{~min}$ at $4^{\circ} \mathrm{C}$ before the serum was removed and later analysed for potassium and sodium concentration by flame photometry (Corning Clinical Flame Photometer 410C; Corning Ltd., Halstead, Essex, UK) and osmolality analysis by freezing point depression (Gonotec Osmomat auto Cryoscopic Osmometer; Gonotec, Berlin, Germany). Haemoglobin concentration was measured in duplicate using the cyanmethaemoglobin method. Haematocrit was determined by micro-centrifugation and measured in triplicate. Using the method of Dill and Costill (1974), blood and plasma volume changes were calculated from haemoglobin concentrations and haematocrit values. A $100 \mu \mathrm{l}$ sample of anticoagulated blood was pipetted into $0.3 \mathrm{M}$ perchloric acid in a ratio of 1:10 in duplicate for analysis of glucose by the GOD-PAP method (Randox Laboratories Ltd., Crumbin, UK) and lactate by fluorimetry using the method outlined by Maughan (1982). Plasma arginine vasopressin and aldosterone concentrations were measured by enzyme immunoassay (Enzyme Immunoassay; Enzo Life Sciences, Ann Arbor, MI, USA) using $100 \mu \mathrm{l}$ samples. Samples were measured in duplicate.

The total volume of each urine sample was measured and a $5 \mathrm{ml}$ sample was retained. This was analysed for osmolality through freezing point depression (Gonotec Osmomat auto Cryoscopic Osmometer; Gonotec, Berlin, Germany). 
208 Statistical analysis

209 Data were checked for normality of distribution using Shapiro-Wilks tests. All samples were

210 normally distributed and subsequently, either paired samples t-tests or repeated measures

211 ANOVA was performed. Post-hoc paired samples t-tests with Bonferroni correction were

212 performed to identify where statistical differences occurred when significant main or

213 interaction effects were observed. Linear regression values and Pearson's product moment

214 correlation coefficients were calculated when appropriate. Linear regression was used to

215 examine the change in plasma vasopressin associated with the change in serum osmolality.

216 Correlation analysis was calculated between variables deemed to be closely related in terms

217 of physiological and behavioural mechanisms related to water balance. Statistical

218 significance was accepted when $\mathrm{p}<0.05$. Data expressed as mean \pm SD.

219

220 
Results

Blood samples were collected from eight subjects due to cannulation problems in two subjects. Despite not being continuous data, the time points in Figures 3, 4, 5 and 6 are joined as the points represent progressive time points throughout the trials.

\section{Baseline values}

There was no difference in baseline body mass between the HIIE $(75.57 \pm 7.28 \mathrm{~kg})$ and LO trial $(75.71 \pm 6.98 \mathrm{~kg})(\mathrm{p}=0.496)$. Similar baseline values for urine osmolality (510 $\pm 248 \mathrm{v}$ $507 \pm 270$ mOsmol. $\mathrm{kg}^{-1}$ for HIIE and LO trials respectively), serum osmolality (285 $\pm 4 \mathrm{v}$ $284 \pm 3$ mOsmol.kg ${ }^{-1}$ for HIIE and LO trials respectively) and subjective feelings of thirst (53 $\pm 21 \mathrm{v} 40 \pm 15$ for HIIE and LO trials respectively) and mouth dryness (52 $\pm 22 \mathrm{v} 42 \pm 16$ for HIIE and LO trials respectively) were observed, suggesting subjects arrived in a similar state of euhydration (Sawka et al. 2007) (p>0.05).

\section{Water balance}

Body mass loss from the beginning of the trial until after the recovery period following voluntary water intake was similar between trials $(0.77 \pm 0.50 \mathrm{v} 0.85 \pm 0.55 \%$ for HIIE and LO trials respectively) $(\mathrm{p}=0.124)$. Sweat loss was greater in the HIIE trial $(0.78 \pm 0.22 \mathrm{l})$ compared to the LO trial $(0.66 \pm 0.26 \mathrm{l})(\mathrm{p}=0.009)$. In the HIIE trial, subjects consumed more water during the recovery period $(\mathrm{p}<0.0001)$ (Figure 2$)$ but this difference was solely due to a higher water intake during the first 30 min of recovery $(\mathrm{p}=0.006)$ whilst during the final 30 min of the recovery period, water intake was similar $(\mathrm{p}=0.094)$. The increase in water intake between the LO and HIIE trials was positively correlated with the increased sweat losses that also occurred ( $\mathrm{r}=0.731, \mathrm{p}=0.534)$. Expressed as a percentage, the amount of water lost that was replaced was higher in the HIIE trial compared to the LO trial $(44 \pm 29 \mathrm{v} 35 \pm 34 \%$; $\mathrm{p}=0.012$ ). In the HIIE trial, one subject drank more than the water lost (104\%), and the next highest replacement value was $77 \%$. In the LO trial, two subjects replaced $90-100 \%$ with the remaining subjects replacing less than $51 \%$ of the water lost during exercise. Negating water intake, body mass losses from baseline would have been similar: $1.34 \pm 0.36 \%$ in the HIIE trial and $1.26 \pm 0.39 \%$ in the LO trial $(=0.205)$, with only one subject in both trials losing enough water to elicit a greater than $2 \%$ body mass loss. The difference in percentage body mass lost when water was included and negated in the calculation was greater in the HIIE 
254

255

256

257

258

259

260

261

262

263

264

265

266

267

268

269

270

271

272

273

274

275

276

277

278

279

280

281

282

283

284

285

trial $(\mathrm{p}<0.0001)$. There was no difference in urine output at the end of the trial $(0.23 \pm 0.12 \mathrm{v}$ $0.28 \pm 0.12 \mathrm{l}$ for HIIE and LO trials respectively; $\mathrm{p}=0.203$ ).

Serum osmolality was higher in the HIIE trial post-exercise $(p=0.006)$ and after $5(p=0.048)$ and $30 \mathrm{~min}(\mathrm{p}<0.001)$ of the recovery period (Figure 3a). Serum osmolality values were similar across all sample points in the LO trial $(\mathrm{p}>0.05)$ but were elevated above baseline and the recovery period samples post-exercise in the HIIE trial $(\mathrm{p} \leq 0.015)$. In the HIIE trial values had returned to baseline following 5 min of recovery ( $p>0.05$ ).

Serum sodium concentrations post-exercise were higher in the HIIE trial compared to the LO trial $(\mathrm{p}=0.018)$ (Figure 3b). In the HIIE trial, post-exercise concentrations were greater compared to baseline and during the recovery period $(\mathrm{p} \leq 0.015)$ and had returned to baseline after 5 min of the recovery period ( $>>0.05$ ). In the LO trial serum sodium concentrations did not increase above baseline $(\mathrm{p}>0.05)$. Serum potassium concentrations were the same at baseline and similar between trials and sample points (baseline: $4.4 \pm 0.3 \mathrm{v} 4.4 \pm 0.3 \mathrm{mmol.l^{- }}$ ${ }^{1}$; post-exercise: $5.1 \pm 0.3$ v $4.9 \pm 0.4$ mmol. $^{-1}$; $5 \mathrm{~min}: 4.4 \pm 0.3$ v $4.5 \pm 0.3 \mathrm{mmol}^{-1}{ }^{-1}$; $15 \mathrm{~min}$ : $4.6 \pm 0.3 \mathrm{v} 4.5 \pm 0.3$ mmol. $\mathrm{l}^{-1}$; 30min: $4.5 \pm 0.3 \mathrm{v} 4.5 \pm 0.31 \mathrm{mmol}^{-1}$ and $60 \mathrm{~min}: 4.6 \pm 0.3 \mathrm{v}$ $4.4 \pm 0.2$ mmol. $\left.\mathrm{l}^{-1}\right)(\mathrm{p}>0.05)$.

\section{Blood analysis}

At baseline, blood lactate concentrations were similar between trials $(\mathrm{p}=0.914)$ but increased during exercise and remained elevated throughout the recovery period $(\mathrm{p} \leq 0.006)$ (Figure 4$)$. In the HIIE trial, blood lactate concentrations peaked post-exercise and remained elevated above baseline values until $30 \mathrm{~min}$ of the recovery period $(\mathrm{p} \leq 0.015)$.

Plasma vasopressin concentrations were higher in the HIIE trial at post-exercise and after 5 and 30 min of the recovery period $(\mathrm{p}<0.05)$ (Figure $5 \mathrm{a})$. In the HIIE trial, post-exercise vasopressin concentrations increased from baseline $(\mathrm{p}=0.048)$, had a tendency to remain elevated above baseline after 5 min of recovery $(p=0.054)$ and were elevated above baseline values after $30 \mathrm{~min}$ of the recovery period $(\mathrm{p}<0.05)$. In the LO trial concentrations did not change from baseline ( $\mathrm{p}>0.05$ ). In both the HIIE and LO trials, aldosterone concentration did not change from baseline ( $>0.05$ ) (Figure $5 b$ ) but after 30 minute of the recovery period aldosterone concentrations were greater in the HIIE trial compared to the LO trial ( $\mathrm{p}=0.048$ ). 
286 Haemoglobin concentrations increased from baseline (156 \pm 7 and $158 \pm 7$ g.l $^{-1}$ for HIIE and LO respectively) to post-exercise (171 \pm 7 and $163 \pm 8$ g. l $^{-1}$ for HIIE and LO respectively) in both trials $(\mathrm{p}<0.05)$. Haemoglobin concentrations were higher post-exercise in the HIIE trial $(\mathrm{p}<0.05)$ but had returned to baseline concentrations after $15 \mathrm{~min}$ (HIIE) and $5 \mathrm{~min}$ (LO) of the recovery period. A similar response was found for haematocrit values with an increase from baseline to post-exercise in the HIIE $(44.0 \pm 2.5$ to $48.2 \pm 2.3 \%)(\mathrm{p}<0.05)$ and LO (44.5 \pm 2.0 to $45.7 \pm 2.4 \%)(\mathrm{p}<0.05)$ trials. Haematocrit values were higher post-exercise in the HIIE trial $(\mathrm{p}<0.05)$ and returned to baseline at the same rate as haemoglobin concentrations. Plasma volume change from baseline was greater in the HIIE trial compared to the LO trial at post-exercise and after 5, 15 and $30 \mathrm{~min}$ of the recovery period $(\mathrm{p}<0.05)$ (Figure 6a). In the HIIE trial plasma volume was different compared to baseline at post-exercise and after 5 and 15. In the LO trial plasma volume changes from baseline at each sample point were similar ( $>0.05)$. Blood volume changes from baseline were greater in the HIIE trial compared to the LO trial at post-exercise and after 5, 15 and 30 min of the recovery period $(p<0.05)$ (Figure 6b). In the HIIE trial, blood volume decreased from baseline at post-exercise and after 5 and 15 min of the recovery period $(\mathrm{p}<0.0001)$ before returning to baseline values. In the LO trial blood volume had decreased from baseline at post-exercise $(p<0.05)$ but had returned to baseline values by 5 min of the recovery period ( $\mathrm{p}>0.05)$.

\section{Subjective feeling questionnaires}

Reported sensations of thirst peaked in both trials post-exercise (Figure 7a) and tended to be higher in the HIIE trial compared to the LO trial at the post-exercise sample $(p=0.060)$. In the HIIE trial, post-exercise reported sensations of thirst were greater than baseline and during the recovery period $(\mathrm{p}<0.0001)$. Reported sensations of mouth dryness peaked in both trials post-exercise (Figure $7 \mathrm{~b}$ ) and tended to be higher in the HIIE trial compared to the LO trial at post-exercise $(\mathrm{p}=0.060)$. There was no difference between trials at the other sample points ( $>00.05)$. In the HIIE trial post-exercise reported sensations of mouth dryness were greater than baseline and during the recovery period $(\mathrm{p}<0.0001)$.

\section{Correlations}

In the HIIE trial serum sodium concentrations were positively correlated to blood lactate concentrations and serum osmolality (Table 1). Serum osmolality was positively correlated to blood lactate concentrations, vasopressin and aldosterone concentrations and sensations of 
319 thirst and mouth dryness. Vasopressin concentrations were positively correlated to blood 320 lactate concentrations but there was no correlation with aldosterone concentrations. In the 321 LO trial correlations were not found between serum osmolality, serum sodium 322 concentrations, blood lactate concentrations and vasopressin and aldosterone concentrations.

324 Core and skin temperature

325 Core temperature peaked at the end of exercise in both the HIIE (38.2 $\left.\pm 0.3^{\circ} \mathrm{C}\right)$ and $\mathrm{LO}(37.6$ $326 \pm 0.3^{\circ} \mathrm{C}$ ) trials. Core temperature was greater at 30, 40, 50 and $60 \mathrm{~min}$ of the exercise period 327 and remained elevated after the first 10 min of the recovery period in the HIIE trial compared to the LO trial $(\mathrm{p}<0.05)$. Skin temperatures were similar between trials at all time points and mean skin temperature over the duration of the trials was similar $\left(31.6 \pm 1.1 \mathrm{v} 31.6 \pm 1.2^{\circ} \mathrm{C}\right.$ for HIIE and LO trials respectively) ( $\mathrm{p}>0.05)$.

331

332 Heart rate, rating of perceived exertion and thermal sensation

333 During the exercise period of the trials, heart rate was significantly higher during the HIIE 334 trial (158 $\pm 12 \mathrm{v} 110 \pm 10$ beats. $\left.\mathrm{min}^{-1}, \mathrm{p}<0.0001\right)$, with differences occurring at 10, 20, 30, 33540 , 50 and $60 \mathrm{~min}$ of exercise. Thermal sensation was higher after $20(5 \pm 1 \mathrm{v} 3 \pm 1$, $336 \mathrm{p}<0.0001$ ), 30 (6 $\pm 1 \mathrm{v} 4 \pm 1, \mathrm{p}<0.0001), 40$ (6 $\pm 1 \mathrm{v} 4 \pm 1, \mathrm{p}<0.0001), 50$ (6 $41 \mathrm{v} 4 \pm 1$, $337 \mathrm{p}<0.0001)$ and $60 \min (6 \pm 2 \mathrm{v} 4 \pm 1, \mathrm{p}<0.0001)$ of the exercise period in the HIIE trial. 338 There was no difference in thermal sensation during the baseline and recovery periods 339 ( $>0.05)$. Ratings of perceived exertion were higher in the HIIE trial after $10(14 \pm 2 \mathrm{v} 10 \pm$ 340 2, p=0.006), 20 (15 \pm 1 v $11 \pm 2, p<0.0001), 30$ (16 \pm 2 v $11 \pm 2, p<0.0001), 40$ (16 \pm 2 v 11 $341 \pm 3, \mathrm{p}<0.0001), 50(17 \pm 2 \mathrm{v} 11 \pm 2, \mathrm{p}<0.0001)$ and $60 \min (17 \pm 2 \mathrm{v} 11 \pm 2, \mathrm{p}<0.0001)$ of the 342 exercise period. 
Discussion

345 The aim of the study was to assess voluntary water intake following either a period of HIIE 346 or continuous exercise. The exercise conditions were chosen to generate significant 347 differences in blood lactate concentrations in order to examine the effects on the 348 physiological mechanisms responsible for voluntary water intake. The 60 minutes of exercise under the two conditions achieved approximately the same work loads (366 kJ) and a clearly significant difference in blood lactate concentrations.

351

Water intake in the HIIE trial was greater during the first 30 min after exercise. Despite the greater water intake, body mass loss was similar between trials primarily due to the increased sweat loss recorded in the HIIE trial. It appeared that the increased water intake could be mainly related to the increased sweat losses. Body mass loss in both trials was greater than $0.8 \%$ and so would have stimulated sensations of thirst (Wolf, 1950) yet were not greater than $2 \%$ suggesting that rapid rehydration through water intake may have not been necessary (Sawka et al., 2007).

359

However, there was a wide range in the individual response to water intake with the amount of water replaced (12-104\% in the HIIE trial and 0-94\% in the LO trial), indicating that water intake replacement was highly variable. Nevertheless the water replacement helped alleviate thirst sensations in the HIIE trial indicated by the reduction in reported sensations of thirst following the onset of the water intake period. This adds strength to the notion that when ad libitum water is allowed then individuals consume sufficient amounts to alleviate sensations of thirst despite not replacing all of the water lost during exercise (Noakes, 2007). It must be noted that the sensation of thirst is complicated and can be affected and influenced by additional variables not measured in the current study. In addition to those measured, oropharyngeal reflexes, absorption rate and fluid capacity of the gastrointestinal system (Greenleaf, 1992) and stomach distension (Rolls et al., 1980) have all been linked to sensations of thirst. Therefore, it would seem that in the current study, the variables measured would not completely explain all of the variance in thirst and voluntary water intake.

The sensation of thirst has been suggested to arise when serum osmolality is greater than 290 mOsmol.kg-1 (Phillips, Rolls, Ledingham, Forsling, \& Morton, 1985). This may provide explanation as to why subjects in the present study consumed water despite body mass losses 
not greater than $2 \%$. In the HIIE trial, osmolality first increased above the threshold value post-exercise before decreasing below this value between 15 and $30 \mathrm{~min}$ of the recovery period, whilst in the LO trial, osmolality values did not increase above 290 mOsmol.kg-1 . In the HIIE trial, despite elevated serum osmolality after 5 and 15 min of the recovery period, sensations of thirst had decreased from peak post-exercise values following the onset of drinking. It appears that the premise of a threshold for thirst works only to initiate drinking and once this has occurred then the effect of the threshold for thirst is diminished. As a result, water intake during the final 30 min of the HIIE trial was similar to the LO trial confirming that satiation of water intake occurs quickly following an initial bout of drinking (Rolls et al., 1980). Closer monitoring of the water intake period, particularly during the first 5 min would have allowed greater interrogation of water intake behaviour in response to exercise.

It has been hypothesised that the efflux of sodium ions from the vascular space to the intracellular space is reduced by the negatively charged lactate ions produced following HIIE, thus causing an increase in serum sodium concentration and subsequently, serum osmolality. In the current study the difference in serum osmolality at post-exercise between trials was approximately $10 \mathrm{mOsmol} . \mathrm{kg}^{-1}$, whilst the difference in serum sodium concentration was approximately 3 mmol. $\mathrm{l}^{-1}$. Using the formula assessed by Worthley, Guerin, and Pain (1987), the change in serum osmolality (12 mOsmol. $\left.\mathrm{kg}^{-1}\right)$ in the HIIE trial from baseline to after exercise was not completely accounted for by the change in serum sodium concentration $(2 * 4$ mmol. $l^{-1}$ ). Therefore it appeared that the change in blood lactate concentration was a direct contributing factor to the increase in serum osmolality (contribution of 4 mOsmol.kg-1). The effect of blood lactate concentrations on serum osmolality values, both directly and indirectly through the increase of serum sodium concentrations, would have contributed to the osmotically driven release of vasopressin and potentially contributed to the increased consumption of water in the HIIE trial (Phillips et al., 1985).

Prior to the onset of thirst stimulated water intake, vasopressin is released to increase water reabsorbtion in the kidneys (Bankir, 2001). Vasopressin release will increase until maximum anti-diuresis has been reached (Thompson et al., 1986). In the current study there was a large increase in plasma vasopressin concentration following the high intensity exercise when serum osmolality values were above the reported threshold value. Vasopressin concentration remained elevated above baseline values throughout the HIIE trial, consistent with serum osmolality remaining above the threshold value outlined. Vasopressin concentration has been 
412 widely shown to decrease quickly (2.5 - $15 \mathrm{~min}$ ) following initiation of drinking (Burrell, 413 Lambert, \& Baylis, 1991; Figaro \& Mack, 1997; Geelen et al., 1984; Seckl, Williams, \& 414 Lightman, 1986). However in these latter studies serum osmolality decreased at either a 415 similar rate (Burrell et al., 1991) or at a slightly delayed rate (30-60 min) (Seckl et al., 1986).

416 In the present study vasopressin concentration remained elevated, whilst thirst sensations 417 decreased after the initial post-exercise peak. Again, this is perhaps related to sensations of 418 thirst becoming quickly satiated once water intake occurs and also suggests that vasopressin 419 is not a direct stimulus of thirst. Increased serum osmolality increases vasopressin 420 concentrations and sensations of thirst, however it appeared that in the current study, water 421 intake satiated sensations of thirst quickly, whereas serum osmolality and vasopressin 422 concentrations were more delayed in returning to baseline levels following water intake. In 423 conjunction with the decrease in water intake during the final 30 minute period it would also 424 suggest that the increased blood lactate concentration and serum osmolality relationship may 425 have had an effect on maintaining vasopressin concentrations.

427 Although the total work rates performed throughout the trials were similar they were not 428 matched precisely. However, the study was effective in achieving its purpose of generating 429 significant differences in blood lactate concentrations between exercise conditions.

431 During the recovery period it appeared that two main variables were influencing the decrease 432 in serum osmolality from post-exercise peak values. The reduction of blood lactate 433 concentration and the intake of water both contributed to decreasing serum osmolality. As 434 the effect of no water intake was not assessed, determining the relative contributing effect of 435 each variable was difficult. However, when the effect of preventing or delaying water intake 436 following HIIE was assessed, similar decreases in serum osmolality, blood lactate and serum 437 sodium concentrations were found (Mears and Shirreffs, unpublished data). Delaying water 438 intake resulted in a similar voluntary water intake despite reduced serum osmolality values, suggesting that once the desire to drink arose, sensations remained until satiated.

441 Conclusion

442 In conclusion, water intake following a period of HIIE was greater than an exercise period of 443 low intensity continuous exercise. The increased water intake in the HIIE trial was mainly 444 attributed to the increased water losses. In addition, the result of an increase in serum 445 osmolality and subsequent vasopressin release caused by an increased blood lactate 
446 concentration in combination with an increased serum sodium concentration may have also 447 contributed to the increased water intake.

448 
449 Acknowledgements

450 This research was, in part, funded by a grant from the European Hydration Institute. 451 
452

453

454

455

456

457

458

459

460

461

462

463

464

465

466

467

468

469

470

471

472

473

474

475

476

477

References

Bankir. L. (2001). Antidiuretic action of vasopressin: quantitative aspects and interaction between V1a and V2 receptor-mediated effects. Cardiovascular Research, 51, 372-390.

Burrell, L.M., Lambert, H.J., \& Baylis, P. H. (1991). The effect of drinking on atrialnatriuretic-peptide, vasopressin and thirst appreciation in hyperosmolar man. Clinical Endocrinology, 35, 229-234.

Cheuvront, S.N., \& Haymes, E.M. (2001). Ad libitum fluid intakes and thermoregulatory responses of female distance runners in three environments. Journal of Sports Sciences, 19, 845-854.

Convertino, V.A., Keil, L.C., Bernauer, E.M., \& Greenleaf, J.E. (1981). Plasma-volume, osmolality, vasopressin, and renin-activity during graded-exercise in man. Journal of Applied Physiology, 50, 123-128.

Dill, D.B., \& Costill, D.L. (1974). Calculation of percentage changes in volumes of blood, plasma, and red-cells in dehydration. Journal of Applied Physiology, 37, 247-248.

Dugas, J.P., Oosthuizen, U., Tucker, R., \& Noakes, T.D. (2009). Rates of fluid ingestion alter pacing but not thermoregulatory responses during prolonged exercise in hot and humid conditions with appropriate convective cooling. European Journal of Applied Physiology, 105, 69-80.

Figaro, M.K., \& Mack, G.W. (1997). Regulation of fluid intake in dehydrated humans: Role of oropharyngeal stimulation. American Journal of Physiology-Regulatory Integrative and Comparative Physiology, 272, R1740-R1746.

Geelen, G., Keil, L.C., Kravik, S.E., Wade, C.E., Thrasher, T.N., Barnes, P.R., Pyka, G., Nesvig, C., \& Greenleaf, J.E. (1984). Inhibition of plasma vasopressin after drinking in dehydrated humans. American Journal of Physiology, 247, R968-R971.

Greenleaf. J.E. (1992). Problem - Thirst, drinking behavior, and involuntary dehydration. Medicine and Science in Sports and Exercise, 24, 645-656. 
479 Hew-Butler, T., Noakes, T.D., Soldin, S.J., \& Verbalis, J.G. (2008a). Acute changes in

480

481

482

483

484

485

486

487

488

489

490

491

492

493

494

495

496

497

498

499

500

501

502

503 endocrine and fluid balance markers during high-intensity, steady-state, and prolonged endurance running: unexpected increases in oxytocin and brain natriuretic peptide during exercise. European Journal of Endocrinology, 159, 729-737.

Maughan, R.J. (1982). A simple, rapid method for the determination of glucose, lactate, pyruvate, alanine, 3-hydroxybutyrate and acetoacetate on a single 20- $\mu$ l blood-sample. Clinica Chimica Acta, 122, 231-240.

Noakes, T.D. (2007) Drinking guidelines for exercise; What evidence is there that athletes should drink "as much as tolerable”, "to replace the weight lost during exercise” or "ad libitum”? Journal of Sports Sciences, 25, 781-796.

Nose, H., Takamata, A., Mack, G.W., Oda, Y., Okuno, T., Kang, D.H., \& Morimoto, T. (1991). Water and electrolyte balance in the vascular space during graded-exercise in humans. Journal of Applied Physiology, 70, 2757-2762.

Phillips, P.A., Rolls, B.J., Ledingham, J.G.G., Forsling, M.L., \& Morton, J.J. (1985). Osmotic thirst and vasopressin release in humans - a double-blind crossover study. American Journal of Physiology, 248, R645-R650.

Ramanathan, N.L. (1964). New weighting system for mean surface temperature of human body. Journal of Applied Physiology, 19, 531-533.

Rolls, B.J., Wood, R.J., Rolls, E.T., Lind, H., Lind, W., \& Ledingham, J.G.G. (1980). Thirst following water-deprivation in humans. American Journal of Physiology, 239, R476R482.

Sawka, M.N., Burke, L.M., Eichner, E.R., Maughan, R.J., Montain, S.J., \& Stachenfeld, N.S. (2007). Exercise and fluid replacement. Medicine and Science in Sports and Exercise, 39, 377-390.

Seckl, J.R., Williams, T.D.M., \& Lightman, S.L. (1986). Oral hypertonic saline causes transient fall of vasopressin in humans. American Journal of Physiology, 251, R214R217. 
506 Sjøgaard, G., Adams, R.P., \& Saltin, B. (1985). Water and ion shifts in skeletal-muscle of humans with intense dynamic knee extension. American Journal of Physiology, 248, R190-R196.

Stricker, E.M., \& Verbalis, J.G. (1988). Hormones and behavior - the biology of thirst and sodium appetite. American Scientist, 76, 261-267.

511 Thompson, C.J., Bland, J., Burd, J., \& Baylis, P.H. (1986). The osmotic thresholds for thirst and vasopressin release are similar in healthy man. Clinical Science, 71, 651-656.

513 Wolf, A.V. (1950). Thirst; physiology of the urge to drink and problems of water lack. Springfield, IL: Charles C Thomas Publisher.

515 Wong, S.H., Williams, C., Simpson, M., \& Ogaki, T. (1998). Influence of fluid intake pattern on short-term recovery from prolonged, submaximal running and subsequent exercise capacity. Journal of Sports Sciences, 16, 143-152.

518 Worthley, L.I., Guerin, M., \& Pain, R.W. (1987). For calculating osmolality, the simplest formula is the best. Anaesthesia and Intensive Care 15, 199-202. 
List of figures

521 Figure 1 Schematic diagram indicating the testing protocol. Arrows represent sampling 522 points. SFQ denotes subjective feelings questionnaire

523 Figure 2 Voluntary water intake during each trial. ${ }^{\dagger}$ denotes difference between trials, * 524 denotes different from 30-60 $\min (\mathrm{p}<0.05)$

525 Figure 3 Serum osmolality (a) and serum sodium concentrations (b) over the duration of each 526 trial. $^{\dagger}$ different between trials, ${ }^{*}$ different from baseline, ${ }^{\#}$ different to post-exercise $(\mathrm{p}<0.05)$.

527 B denotes baseline sample, $\mathrm{PE}$ denotes post-exercise sample

528 Figure 4 Blood lactate concentrations over the duration of each trial. ${ }^{\dagger}$ different between 529 trials, * different to baseline, ${ }^{*}$ different to post-exercise, ${ }^{\wedge}$ different to $5 \mathrm{~min},{ }^{\S}$ different to $53015 \mathrm{~min}(\mathrm{p}<0.05)$. B denotes baseline sample, PE denotes post-exercise sample

531 Figure 5 Vasopressin (a) and aldosterone (b) concentration over the duration of each trial. ${ }^{\dagger}$ 532 different between trials, ${ }^{*}$ different to baseline, ${ }^{\#}$ different to post exercise $(\mathrm{p}<0.05)$. B denotes 533 baseline sample, $\mathrm{PE}$ denotes post-exercise sample

534 Figure 6 Plasma volume (a) and blood volume (b) changes from baseline values over the 535 duration of each trial. ${ }^{\dagger}$ different between trials, ${ }^{*}$ different to baseline values, ${ }^{*}$ different to 536 the post exercise change, ${ }^{\wedge}$ different to the baseline to $5 \mathrm{~min}$ change $(\mathrm{p}<0.05)$. B denotes 537 baseline sample, $\mathrm{PE}$ denotes post-exercise sample

538 Figure 7 Sensations of thirst (a) and mouth dryness (b) over the duration of each trial. 539 different to baseline in the HIIE trial, * different to post exercise in the HIIE trial, ^ different 540 to $5 \mathrm{~min}$ in the HIIE trial $(\mathrm{p}<0.05)$. B denotes baseline sample, PE denotes post-exercise 541 sample 


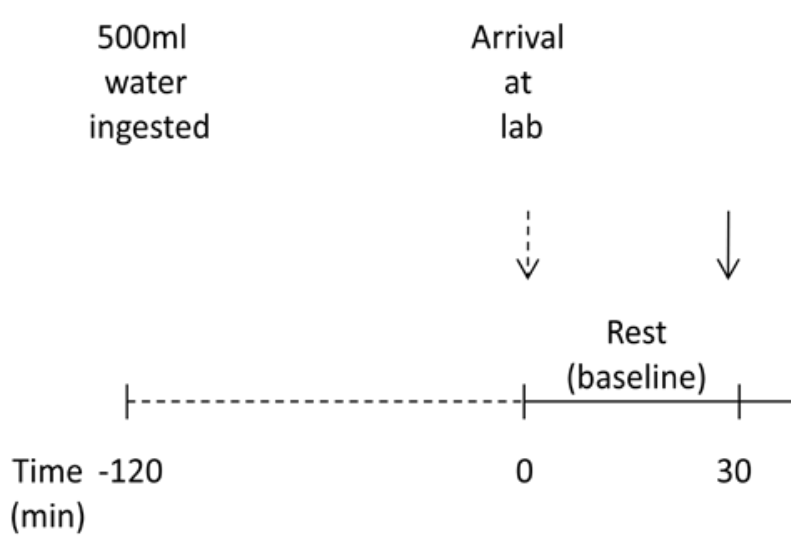

544

545 Figure 1

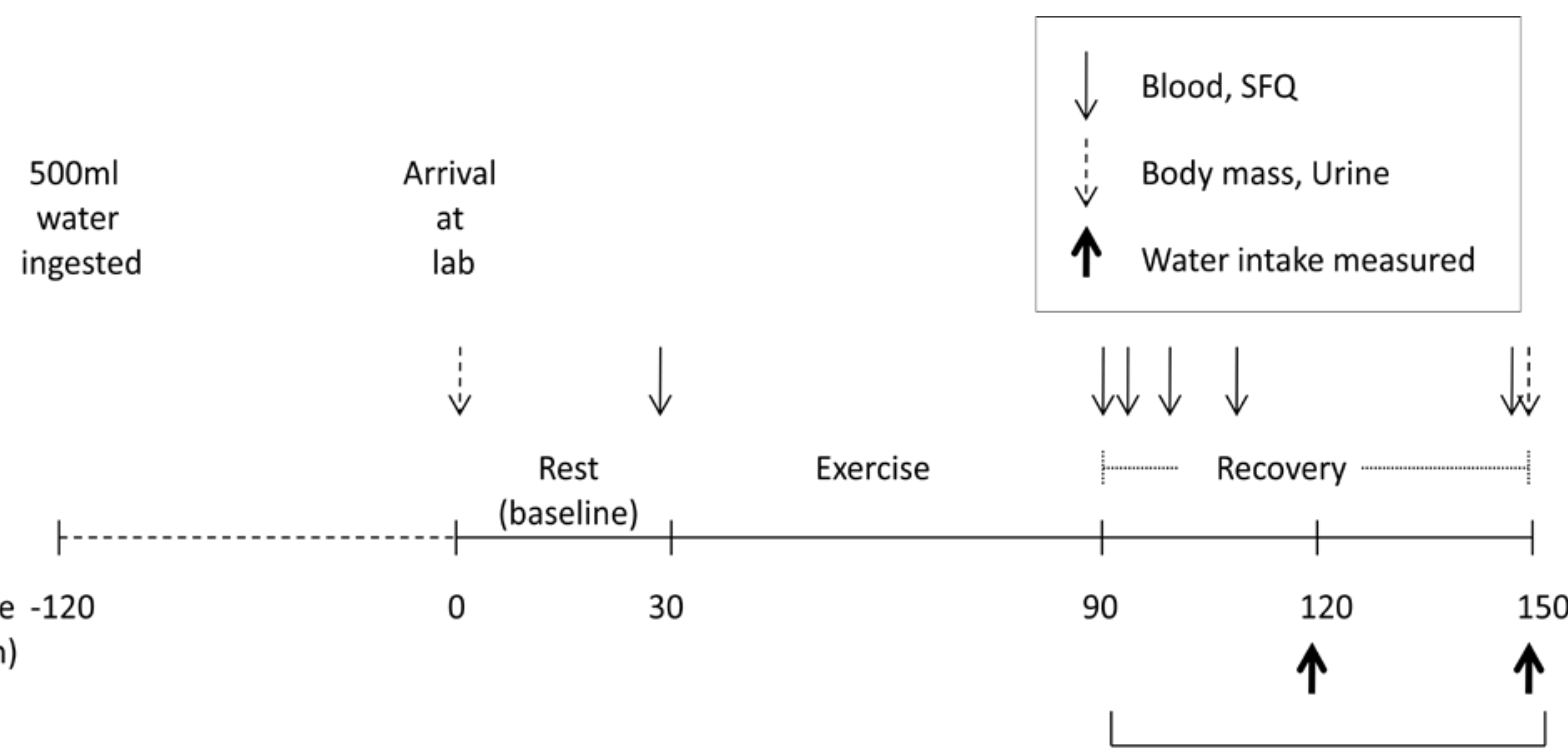

Ad libitum water intake 


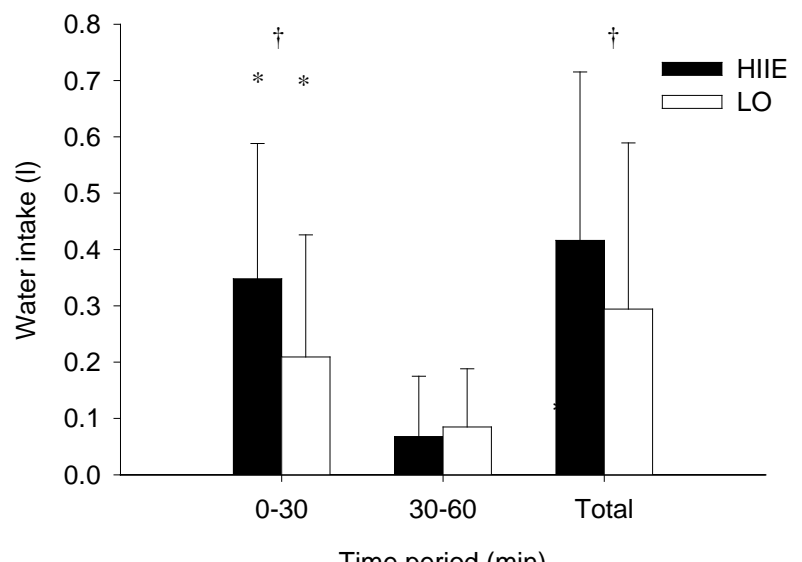

548 Figure 2

Time period (min) 

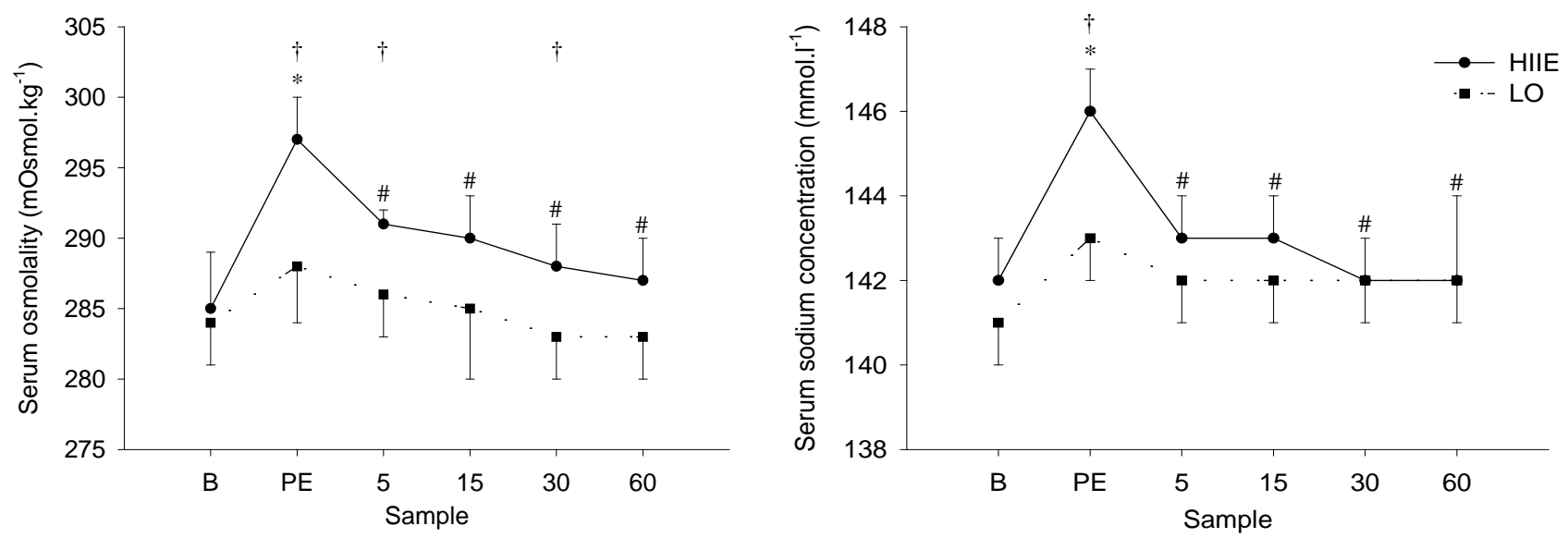

551 Figure 3

552 
554 Figure 4

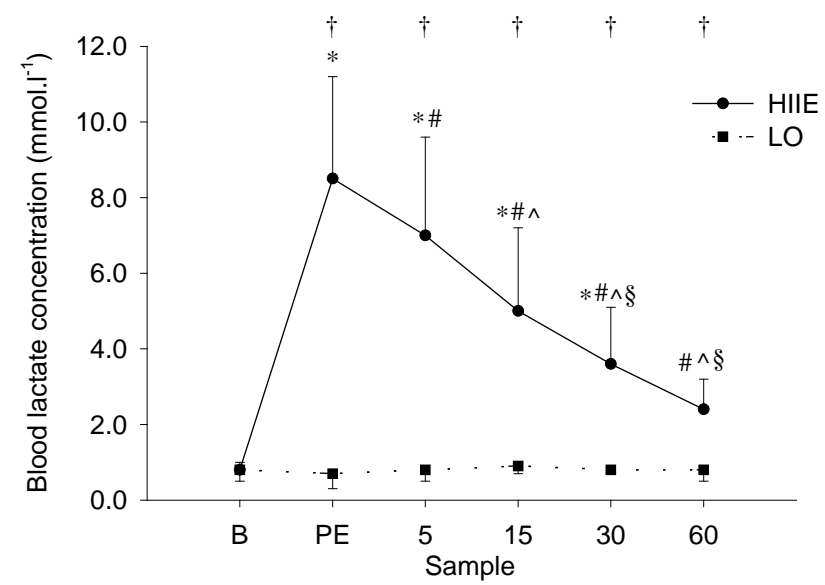



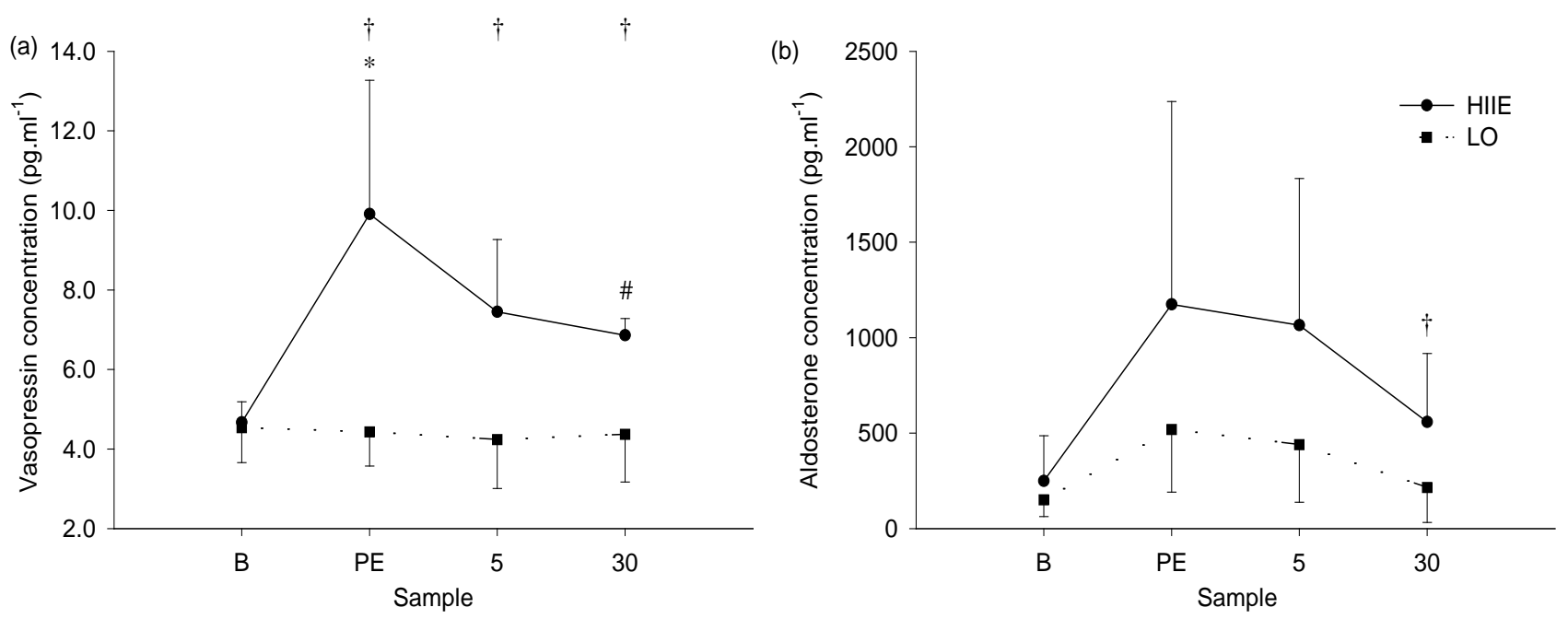

557 Figure 5

558 

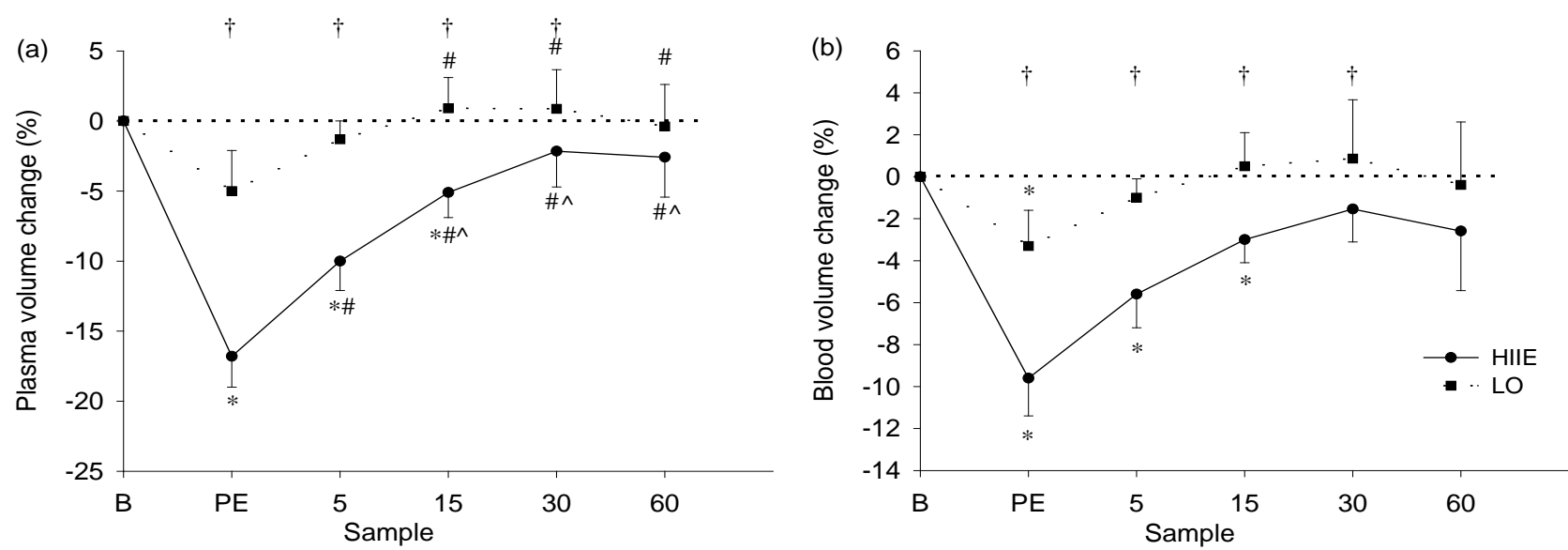

Figure 6

561 

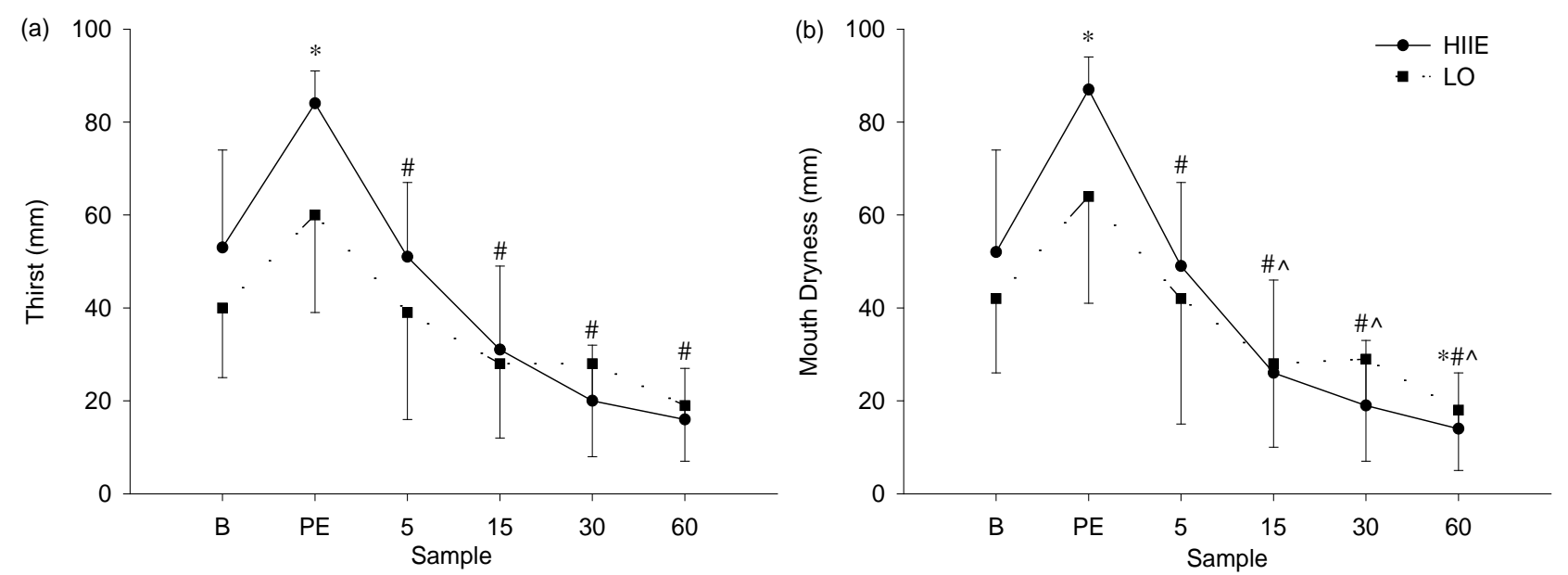

$\begin{array}{ll}562 & \\ 563 & \text { Figure } 7\end{array}$

564 
Table 1 Correlation coefficients between measured variables in each trial $\left({ }^{*} \mathrm{p}<0.05\right.$; $* * \mathrm{p}<0.0001$ )

\begin{tabular}{|c|c|c|c|c|c|}
\hline \multirow[b]{2}{*}{ Variables } & & \multicolumn{2}{|c|}{ HIIE } & \multicolumn{2}{|c|}{ LO } \\
\hline & & $\mathbf{r}$ & $\mathbf{p}$ & $\mathbf{r}$ & $\mathbf{p}$ \\
\hline \multirow[t]{6}{*}{ Serum osmolality } & Serum sodium concentration & 0.470 & $0.001^{*}$ & 0.223 & 0.142 \\
\hline & Blood lactate concentration & 0.655 & $<0.0001^{* *}$ & 0.170 & 0.265 \\
\hline & Vasopressin concentration & 0.661 & $<0.0001^{* *}$ & -0.195 & 0.320 \\
\hline & Aldosterone concentration & 0.545 & $0.003 *$ & 0.373 & 0.050 \\
\hline & Thirst & 0.419 & $0.004 *$ & 0.293 & 0.051 \\
\hline & Mouth dryness & 0.411 & $0.005^{*}$ & 0.211 & 0.165 \\
\hline Serum sodium & Blood lactate concentration & 0.608 & $<0.0001^{* *}$ & 0.201 & 0.184 \\
\hline \multirow[t]{4}{*}{ concentration } & Vasopressin concentration & 0.663 & $<0.0001^{* *}$ & 0.131 & 0.506 \\
\hline & Aldosterone concentration & 0.415 & $0.028 *$ & 0.207 & 0.506 \\
\hline & Thirst & 0.521 & $<0.0001^{* *}$ & 0.264 & 0.079 \\
\hline & Mouth dryness & 0.552 & $<0.0001^{* *}$ & 0.243 & 0.108 \\
\hline Blood lactate & Vasopressin concentration & 0.657 & $<0.0001^{* *}$ & -0.307 & 0.112 \\
\hline \multirow[t]{3}{*}{ concentration } & Aldosterone concentration & 0.476 & $0.010^{*}$ & -0.096 & 0.628 \\
\hline & Thirst & 0.518 & $<0.0001^{* *}$ & 0.270 & 0.073 \\
\hline & Mouth dryness & 0.468 & $0.001^{*}$ & 0.265 & 0.078 \\
\hline Vasopressin & Aldosterone concentration & 0.317 & 0.100 & -0.119 & 0.547 \\
\hline \multirow[t]{2}{*}{ concentration } & Thirst & 0.517 & $0.005^{*}$ & -0.242 & 0.214 \\
\hline & Mouth dryness & 0.517 & $0.004 *$ & -0.270 & 0.164 \\
\hline Aldosterone & Thirst & 0.226 & 0.248 & 0.309 & 0.110 \\
\hline concentration & Mouth dryness & 0.159 & 0.419 & 0.262 & 0.177 \\
\hline Thirst & Mouth dryness & 0.976 & $<0.0001^{* *}$ & 0.972 & $<0.0001^{* *}$ \\
\hline
\end{tabular}

